\title{
Deep-water running training at moderate intensity and high intensity improves pain, disability, and quality of life in patients with chronic low back pain: a randomized clinical trial
}

\author{
Ana C Kanitz', Bruna Machado', Denise Rodrigues², Guano Zambelli', André Ivaniski', Natália Carvalho', Thaís Reichert', \\ Edmilson Pereira', Rochelle Rocha', Rodrigo Sudatti ${ }^{3}$, Luiz F Martins ${ }^{1}$
}

'Federal University of Rio Grande do Sul. Porto Alegre. Brasil. ${ }^{2}$ Federal University of Uberlândia. Uberlândia. Brasil. ${ }^{3}$ Federal University of Santa Catarina. Trindade. Brasil.

doi: 10.18176 /archmeddeporte.00023

Recibido: 28/04/2020

Aceptado: 10/12/2020

Key words:

Exercise. Aerobic exercise. Exercise intensity. Aquatic exercise.

Deep-water running. Back pain. Chronic pain. Low back pain. Health professions.

\section{Summary}

Objective: The present study aimed to verify the influence of training intensity in the aquatic environment on pain, disability, physical capacity, and quality of life in patients with chronic low back pain. Design/Setting: A randomized clinical trial. Subjects: Twenty-two patients with chronic low back pain of both sexes (13 women and 9 men) participated in the study.

Material and method: One group performed deep-water walking/running training at moderate intensity (MIT) and a second group performed deep-water walking/running training at high intensity (HIT). Pain, disability, peak oxygen uptake $\left(\mathrm{VO}_{2 \text { peak }}\right)$, and quality of life were assessed before and after an intervention.

Results: Decreases in pain and disability were observed within both groups, without differences in these parameters between training groups. $\mathrm{VO}_{2 \text { peak }}$ did not change in either group after the training intervention. The results of the HIT group showed more significant improvements in quality of life than that of the MIT group, highlighting the social domain, psychological domain, and general quality of life. Both groups presented significant improvements in the physical and environmental domains of quality of life.

Conclusions: Deep-water aerobic exercise training seems to be effective for improving pain symptoms and reducing the disability of people with chronic low back pain. These improvements seem to be independent of the intensity at which the training is performed. In addition, improving pain and disability does not directly reflect all areas of quality of life. In this case, the group that performed the intervention at high intensity achieved more significant improvements in quality of life.
Palabras clave: Ejercicio. Ejercicio aeróbico. Intensidad de ejercicio. Ejercicio acuático. Carrera en aguas profundas. Dolor de espalda.

Dolor crónico. Dolor lumbar. Profesiones de la salud.
El entrenamiento de carrera de piscina profunda de intensidad moderada y alta intensidad mejora el dolor, la discapacidad y la calidad de vida en pacientes con dolor lumbar crónico: un ensayo clínico aleatorizado

\section{Resumen}

Objetivo: El presente estudio tuvo como objetivo verificar la influencia de la intensidad del entrenamiento en el ambiente acuático sobre el dolor, la discapacidad, la capacidad física y la calidad de vida en pacientes con dolor lumbar crónico. Diseño/ entorno: un ensayo clínico aleatorizado. Sujetos: Veintidós pacientes con dolor lumbar crónico de ambos sexos (13 mujeres y 9 hombres) participaron en el estudio.

Material y método: Un grupo realizó entrenamiento de caminar/correr en aguas profundas a intensidad moderada (MIT) y un segundo grupo realizó entrenamiento de caminar/correr en aguas profundas a alta intensidad (HIT). El dolor, la discapacidad, el consumo máximo de oxígeno $\left(\mathrm{VO}_{2 \text { pico }}\right)$ y la calidad de vida se evaluaron antes y después de una intervención.

Resultados: Se observaron disminuciones en el dolor y la discapacidad en ambos grupos, sin diferencias en estos parámetros entre los grupos de entrenamiento. $\mathrm{VO}_{2 \text { peak }}$ no cambió en ninguno de los grupos después de la intervención de entrenamiento. Los resultados del grupo HIT mostraron mejoras más significativas en la calidad de vida que la del grupo MIT, destacando el dominio social, el dominio psicológico y la calidad de vida general. Ambos grupos presentaron mejoras significativas en los dominios físicos y ambientales de la calidad de vida.

Conclusiones: El entrenamiento de ejercicio aeróbico en aguas profundas parece ser efectivo para mejorar los síntomas de dolor y reducir la discapacidad de las personas con dolor lumbar crónico. Estas mejoras parecen ser independientes de la intensidad a la que se realiza el entrenamiento. Además, mejorar el dolor y la discapacidad no refleja directamente todas las áreas de calidad de vida. En este caso, el grupo que realizó la intervención a alta intensidad logró mejoras más significativas en la calidad de vida. 


\section{Introduction}

Currently, musculoskeletal pains are extremely frequent in the world's population, mainly in middle-aged and working-aged adults. They negatively influence the quality of life of people, limiting their performance of daily activities ${ }^{1}$. In this context, low back pain affects about $12 \%$ of the world's population ${ }^{2}$. Chronic low back pain refers to pain in the vertebral region or lumbar paravertebral region; it is considered chronic when it lasts more than 12 weeks ${ }^{3}$. A considerable number of patients who develop chronic symptoms do not respond to conventional therapies ${ }^{4}$ such as physiotherapy and medication. Thus, it is believed that regular mechanical activity, such as that produced by physical exercise, seems to be the most reasonable treatment for patients with chronic low back pain ${ }^{3,5-7}$.

Among the indicated exercises, those performed in the aquatic environment stand out, since they have great influence on the sensorial system due to the ability of the hydrostatic pressure and water temperature to reduce the sensation of pain ${ }^{8}$. In addition, resting immersion, at thermoneutral temperature $\left(33-35^{\circ} \mathrm{C}\right)^{9}$, is closely linked to muscle relaxation and a sense of well-being ${ }^{10}$. Within this context, exercises in the aquatic environment seem to be an interesting alternative for people with chronic low back pain, because in addition to the benefits reported, aquatic exercises also have different biomechanical characteristics compared to that of the land environment. Deep-water running has no impact on the lower limbs and is also notable for causing spinal decompression compared to walking/running on a treadmill or in a shaIlow pool ${ }^{11}$. In addition, this modality allows one to achieve high aerobic intensities, which offer functional, strength, and resistance benefits ${ }^{11,12}$ that are negatively correlated with the degree of disability and pain.

However, most studies in the literature discussing physical exercise interventions do not achieve a control and a progression of intensity throughout the intervention. In addition, no studies were found comparing the effect of different training intensities on pain and disability in patients with chronic low back pain ${ }^{8,12,13}$. In the aquatic environment, studies have been found that evaluate the effect of hydrotherapy alone or compared with traditional physiotherapy ${ }^{8,13,14}$, but some studies evaluate a systematic training with intensity control in the aquatic environment ${ }^{1,15,16}$. In addition, some authors suggest that physical exercise at higher intensities may provoke an analgesic effect induced by hormonal changes, resulting from a greater release of cortisol and adrenaline ${ }^{1,17}$.

Thus, the practice of regular exercise seems to provide important benefits in the treatment of chronic low back pain and the aquatic environment seems to be a safe environment for practice. However, there are still few studies in the literature regarding this topic, mainly regarding the intensity of the intervention. In this way, the present study aimed to verify the influence of training intensity in the aquatic environment on pain, disability, physical capacity, and quality of life in patients with chronic low back pain. According to the hypothesis of this study, it is believed that both moderate- and high-intensity training will provide important improvements in the evaluated outcomes. However, it is believed that the high-intensity training will maximize the benefits of the participants' physical capacity in a more significant way, which may be reflected in the other outcomes.

\section{Material and method}

\section{Experimental design and problem approach}

The study is characterized as a randomized clinical trial with two groups in parallel. One group (MIT) performed deep-water walking/ running training at moderate intensity, and a second group (HIT) performed deep-water walking/running training at high intensity. A control group was not tested, since the effectiveness of the exercise interventions in the answers of interest are already well documented in the literature $13,5,7,15,16$, leaving a gap in understanding which intensity provides the best benefits. All measurements were taken before the intervention period and $72 \mathrm{~h}$ after the last training session, with all assessments completed within a maximum period of one week after the end of the training. Each evaluation was always carried out by the same researcher, who was specifically trained for this evaluation, and was performed using the same equipment. In addition, the evaluators were blinded to the intervention groups to which the participants belonged. This study was designed following the recommendations of the Consolidated Standards of Reporting Trials (CONSORT) ${ }^{18}$.

\section{Subjects}

Twenty-two physically active patients with chronic low back pain of both sexes (13 women and 9 men) participated in the study. For participation, those interested were required to present with a medical diagnosis of chronic low back pain, with or without irradiation to the lower limbs, for more than 12 weeks. It was not necessary to have previous experience with deep-water running. When included in the study, participants were instructed not to practice other modalities of physical exercise. There was no control over what type of physical activity was performed before the study, as well as, how long they were practicing.

The project was publicized in social networks and local newspapers. Participants were informed of the study objectives, the possibilities of discomfort, and the risks of procedures and interventions. After agreeing to participate in the study, they signed an informed consent form. The study was conducted in accordance with the Declaration of Helsinki and was approved by the Research Ethics Committee of the Federal University of Rio Grande do Sul (registration no: 39789014.6.0000.5347).

After all pre-intervention evaluations, the participants were randomized into the two intervention groups: deep-water walking/running at moderate intensity (MIT; $\mathrm{n}=11$ ) and deep-water walking/running at high intensity $(H I T ; n=11)$. The randomization process was done by a researcher not involved in the evaluations, and the interventions of the study were determined by removing a paper from an opaque envelope in which there were numbers corresponding to each group.

\section{Assessments}

The evaluations were conducted in the Biodynamics Laboratory of Movement of the School of Physical Education, Physiotherapy, and Dance of the Federal University of Rio Grande do Sul. All evaluations were performed individually in only one session of approximately 1 hour. Participants were instructed not to use analgesic medication 24 hours before the evaluations. 
Initially, the participants remained at rest, sitting in a chair with their arms relaxed at the side of their body. They remained in this resting position for 15 minutes. After this period, blood pressure (BP) was measured as a safety measure in preparation for the maximum treadmill test that was performed later (MAPA, Meditech, model ABPM-04). A systolic BP below $140 \mathrm{~mm} \mathrm{Hg}$ and a diastolic BP below $90 \mathrm{~mm} \mathrm{Hg}$ was considered as adequate $\mathrm{BP}^{19}$.

Afterwards, the participants were instructed to respond to the Visual Analogue Scale (VAS) and the Oswestry indexes that assess pain and disability, respectively. Then, they were positioned on the treadmill to begin the maximal test. This test had the objective of evaluating the peak oxygen uptake $\left(\mathrm{VO}_{\text {2peak }}\right)$. The participants were instructed to avoid both the consumption of caffeine and exercise within 24 hours of the test and to avoid eating within 3 hours of the test. We used an INBRAMED treadmill (Porto Alegre, Brazil) and a VO2000 portable gas analyzer from MedGraphics (Ann Arbor, USA). The protocol involved the use of an incremental load, with an initial velocity of $6 \mathrm{~km} / \mathrm{h}$ and an inclination of $1 \%$ for 2 minutes. Afterwards, the inclination was maintained at a fixed level and we increased the velocity to $1 \mathrm{~km} /$ h every 2 minutes until the participant reported exhaustion. The assessment was considered valid when some of the following criteria were met at the end of the test: the estimated maximal heart rate was reached [220 minus the participant's age, in beats per minute (bpm)], a respiratory exchange ratio greater than 1.15 was reached, and an effort perception of 19 [Borg Rating of Perceived Exertion (RPE) Scale, scale range of 6-20)] was appraised ${ }^{20}$. Lastly, the final stage of the evaluation session consisted of completing the World Health Organization Quality of Life (WHOQOL) questionnaire, which evaluates general quality of life in four different domains (physical, psychological, social, and environmental).

\section{Training}

Before starting the training periods, the participants performed four sessions of familiarization with the technique of deep-water running and with the aquatic environment. Deep-water running is carried out with the help of a float vest, which keeps the individual upright without using the foot support at the bottom of the pool. The elbows should be flexed at $90^{\circ}$, the hands closed, and the movement of the upper limbs alternating relative to the movement of the lower limbs.

Study participants were trained on non-consecutive days, twice a week for a period of 12 weeks. In case of failure to participate on one of the training days, an extra session for recovery was scheduled. The trainings were performed in the evening during consecutive hours, administered by the same instructor with experience in aquatic exercises. The classes had a duration of 45 minutes, which were consisted of warm-up, the main exercise period, and stretching. The warm-up period consisted of a walk at a slightly self-selected intensity. The main exercise period included deep-water walking and/or running at the intensities prescribed for each phase of the training and lasted for 35 minutes. Finally, the priority of the stretching portion was to stretch the main muscles used during the main exercise period.

The intensity prescription of both groups was administered with intensities defined according to the heart rate of the second ventilatory threshold $\left(\mathrm{HR}_{\mathrm{VT2}}\right)$. During the classes, each participant used a heart rate
Table 1. 12-week periodization of deep water walking/running training at moderate intensity.

\begin{tabular}{lll}
\hline Week & Volume $\mathrm{x}$ Intensity & $\begin{array}{l}\text { Total } \\
\text { time }\end{array}$ \\
\hline $1,2,3$ and 4 & $7 \times\left(3 \min 85 \% \mathrm{HR}_{\mathrm{VT2}}+2 \mathrm{~min}<85 \% \mathrm{HR}_{\mathrm{VT2}}\right)$ & $35 \mathrm{~min}$ \\
$5,6,7$ and 8 & $7 \times\left(4 \min 90 \% \mathrm{HR}_{\mathrm{VT2}}+1 \mathrm{~min}<85 \% \mathrm{HR}_{\mathrm{VT2}}\right)$ & $35 \mathrm{~min}$ \\
$9,10,11$ and 12 & $7 \times\left(4 \mathrm{~min} 95 \% \mathrm{HR}_{\mathrm{VT2}}+1 \mathrm{~min}<85 \% \mathrm{HR}_{\mathrm{VT2}}\right)$ & $35 \mathrm{~min}$ \\
\hline $\mathrm{HR}_{\mathrm{VT} 2}$ : heart rate of the second ventilatory threshold. &
\end{tabular}

monitor to control the training heart rate $(\mathrm{HR})$ and were allowed a variation of $5 \mathrm{bpm}$ above or below the targeted HR. Table 1 shows the periodization of the 12 weeks of training at moderate-intensity training and training at high-intensity training.

To determine the $\mathrm{HR}_{\mathrm{VT} 2}$ used in the prescription, a maximal deepwater running test was performed. The participants performed the test in a stationary position and at the depth of the shoulders. Participants were attached to the edge of the pool using a cable connected to the float vest. In this way they performed the stride of the race in a deep pool, and with each musical beat one leg should be positioned in front. The test protocol consisted of an initial rate of 85 beats per minute (bpm) for three minutes, increasing by 15 bpm every two minutes, until the individual indicated exhaustion or until the participant does not keep pace with the test. One of the evaluators monitored whether the individual's stride was within the rhythm of each phase of the test. HR was collected every 10 seconds using a heart rate monitor. The $\mathrm{HR}_{\mathrm{VT2}}$ was determined by HR deflection point observed in the graph FC by the intensity ${ }^{12}$.

\section{Statistical analysis}

Descriptive statistics (mean and 95\% confidence interval) were used to report the results. Sample characterization data (at baseline) of both groups (HIT and MIT) were compared by independent T-test and chi-square test. Generalized estimating equations (GEE) and the Bonferroni post hoc test were used to compare the means of all dependent variables (in intention-to-treat and per protocol analysis). Furthermore, the effect size (ES, using Cohen's d) was calculated from the difference in post-training values between the HIT and MIT groups, and classified as small (between 0.2 and 0.5), moderate (between 0.5 and 0.8), or large (0.8 or more $)^{21}$. The statistical significance level was set at $\mathrm{a}=0.05$ for all tests and the statistical software SPSS (version 22.0) was used for all analyses.

\section{Results}

The study started with 22 participants, with 11 in each intervention group. In the MIT group, three patients did not finish the study, one due to changes in working hours, one due to illness, and another by withdrawal. In the HIT group, there were four losses, as two participants abandoned the study and two did not conclude an intervention due to health reasons (Figure 1). All dropouts were invited to return to the final evaluations to perform the intent-to-treat analysis, however, only two participants originally in the HIT group attended. Baseline charac- 
Figure 1. Flow diagram showing the participant's enrollment process, allocation, follow-up and the analysis.

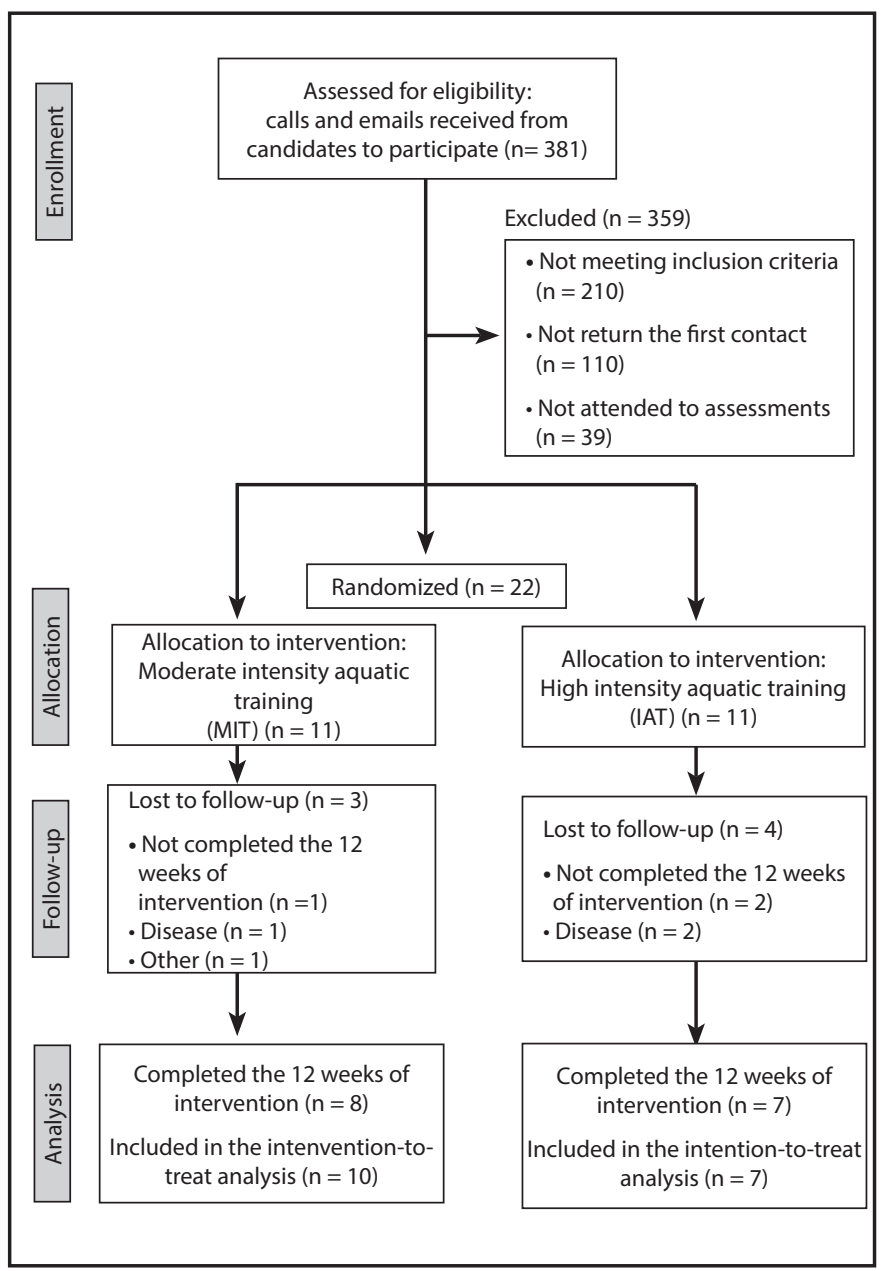

Table 2. 12-week periodization of deep water walking/running training at hight intensity.

\begin{tabular}{lll}
\hline Week & Volume $x$ Intensity & $\begin{array}{l}\text { Total } \\
\text { time }\end{array}$ \\
\hline $1,2,3$ and 4 & $7 \times\left(3 \min 95 \% \mathrm{HR}_{\mathrm{VT2}}+2 \min <85 \% \mathrm{HR}_{\mathrm{VT2}}\right)$ & $35 \mathrm{~min}$ \\
$5,6,7$ and 8 & $7 \times\left(4 \min 100 \% \mathrm{HR}_{\mathrm{VT2}}+1 \mathrm{~min}<85 \% \mathrm{HR}_{\mathrm{VT2}}\right)$ & $35 \mathrm{~min}$ \\
$9,10,11$ and 12 & $7 \times\left(3 \min 100 \% \mathrm{HR}_{\mathrm{VT} 2}+1 \min 105 \% \mathrm{HR}_{\mathrm{VT2}}+\right.$ & $35 \mathrm{~min}$ \\
\hline & $\left.1 \mathrm{~min}<85 \% \mathrm{HR}_{\mathrm{VT2}}\right)$ & \\
\hline
\end{tabular}

$\mathrm{HR}_{\mathrm{IV}:}$ : heart rate of the second ventilatory threshold.

terization of the participants is presented in Table 2. All characteristics were similar between the groups ( $p>0.05)$.

The results regarding pain, disability, and $\mathrm{VO}_{\text {2peak }}$ can be observed in Table 3. Decreases in pain and disability were observed in both groups, as per protocol analysis (pain: $p<0.001$; disability: $p<0.001$ ) and the intention-to-treat analysis (pain: $p<0.001$; disability: $p<0.001$ ) after the training intervention. $\mathrm{VO}_{2 \text { peak }}$ did not change after the training intervention; these results were confirmed according to the protocol $(p=0.675)$
Table 3. Patients' characteristics.

\begin{tabular}{lccc}
\hline & MIT & HIT & p value \\
\hline Age (year) & $41(31$ to 50$)$ & $35(23$ to 48$)$ & 0.666 \\
Body mass $(\mathrm{kg})$ & $76(47$ to 105$)$ & $73(47$ to 85$)$ & 0.811 \\
Height $(\mathrm{cm})$ & $1.66(1.55$ to 1.77$)$ & $1.64(1.47$ to 1.80$)$ & 0.660 \\
BMI (kg/m²) & $27(19$ to 35$)$ & $27(25$ to 30$)$ & 0.737 \\
Duration of & $60(-26$ to 145$)$ & $77(-39$ to 193$)$ & 0.647 \\
symptoms (months) & & & \\
Gender (F/M) & $04 / 04$ & $05 / 02$ & 0.398 \\
\hline
\end{tabular}

MIT: moderate intensity aquatic training; HIT: high intensity aquatic training Comparisons were performed by Independent T-test; $a=0.05$. Data are expresses as mean and confidence interval $95 \%$.

and the intention-to-treat analyses ( $p=0.531$ ). In addition, no differences in pain, disability, and $\mathrm{VO}_{\text {2peak }}$ were observed between the groups.

The results regarding quality of life and its domains can be observed in Table 4. The physical domain in the intention-to-treat analysis showed significant differences in the time effect $(p=0.011)$, demonstrating a significant improvement in both groups with the interventions performed. However, in the protocol analysis, a significant interaction ( $p=0.042$ ) was observed in the physical domain. In the post hoc analysis, we observed that both groups maintained their physical domain values from pre- to post-training and a significant difference was observed only between the post-training groups ( $p=0.009$ ); higher scores in the physical domain were demonstrated in the HIT group compared to that of the MIT group.

In the intention-to-treat analysis of the psychological domain, significant changes with the interventions performed were not present, nor were there differences between the groups in this domain. However, a significant interaction was observed in the protocol analysis $(p=0.003)$. In the post hoc analysis, a significant difference was observed between the post-training groups $(p<0.001)$, as higher scores in the psychological domain were observed in the HIT group compared to those in MIT group. In addition, only the HIT group demonstrated significant improvements when pre-and post-training outcomes were compared. In contrast, the MIT group maintained its values.

The social domain showed a significant interaction in both the intention-to-treat analysis $(p=0.019)$ and the protocol analysis $(p=0.013)$. In the post hoc analysis, differences were observed between posttraining groups (intention-to-treat: $p<0.001$; per protocol: $p<0.001$ ) and a significant improvement was observed in this domain only for the HIT group, from pre- to post-intervention (intention-to-treat: $p=0.013$; per protocol: $p=0.010)$. The MIT group maintained its values after the intervention. The environmental domain had a significant effect on time in both the intention-to-treat analysis $(p=0.020)$ and the protocol analysis ( $p=0.032$ ). Furthermore, showing no difference between groups and no significant interaction in the environmental domain.

Finally, the general quality of life presented significant interaction in the intention-to-treat analysis $(p=0.001)$ and in the protocol analysis $(p=0.006)$. Post hoc analysis demonstrated a significant improvement from pre- to post- intervention only in the HIT group, both in intentionto-treat analysis $(p<0.001)$ and in protocol analysis $(p=0.002)$. The MIT group maintained its values regarding time. 
Table 4. Pain, Oswestry disability Index and $\mathrm{VO}_{2 \text { peak }}$ for moderate intensity aquatic training (MIT) and high intensity aquatic training (HIT) before and after 12 weeks of training.

\begin{tabular}{|c|c|c|c|c|c|c|}
\hline \multirow[t]{2}{*}{ Intention-to-treat analysis } & \multicolumn{3}{|c|}{ MIT } & \multicolumn{3}{|c|}{ HIT } \\
\hline & Baseline & 12 weeks & Change & Baseline & 12 weeks & Change \\
\hline $\begin{array}{l}\text { Pain } \\
\text { (100 mm VAS) }\end{array}$ & $\begin{array}{c}57.0 \\
\text { (45.4 to } 68.6)\end{array}$ & $\begin{array}{c}18.8^{*} \\
\text { (11.4 to } 26.3)\end{array}$ & -38.2 & $\begin{array}{c}58.4 \\
\text { (45.9 to } 70.7)\end{array}$ & $\begin{array}{c}27.4^{*} \\
(11.0 \text { to } 43.8)\end{array}$ & -31.0 \\
\hline $\begin{array}{l}\text { Oswestry } \\
\text { Disability index }\end{array}$ & $\begin{array}{c}10.1 \\
\text { (7.4 to } 12.9)\end{array}$ & $\begin{array}{c}6.0^{*} \\
(3.3 \text { to } 8.7 \text { ) }\end{array}$ & -4.1 & $\begin{array}{c}14.4 \\
(10.6 \text { to } 18.3)\end{array}$ & $\begin{array}{c}9.2^{*} \\
\text { (6.5 to } 11.8)\end{array}$ & -5.2 \\
\hline $\begin{array}{l}\mathrm{VO}_{2 \text { peak }} \\
\left(\mathrm{ml} \cdot \mathrm{kg}^{-1} \cdot \mathrm{min}^{-1}\right)\end{array}$ & $\begin{array}{c}44.5 \\
\text { (39.1 to } 49.9)\end{array}$ & $\begin{array}{c}44 \\
\text { (38.5 to } 50.3)\end{array}$ & 0.5 & $\begin{array}{c}46.2 \\
\text { (37.3 to } 55.1)\end{array}$ & $\begin{array}{c}43.5 \\
\text { (36.7 to } 50.2)\end{array}$ & -2.9 \\
\hline \multirow[t]{2}{*}{ Per protocol analysis } & \multicolumn{3}{|c|}{ MIT } & \multicolumn{3}{|c|}{ HIT } \\
\hline & Baseline & 12 weeks & Change & Baseline & 12 weeks & Change \\
\hline $\begin{array}{l}\text { Pain } \\
\text { (100 mm VAS) }\end{array}$ & $\begin{array}{c}57.0 \\
\text { (45.4 to } 68.6)\end{array}$ & $\begin{array}{c}18.8^{*} \\
\text { (11.4 to } 26.3)\end{array}$ & -38.2 & $\begin{array}{c}59.4 \\
\text { (45.9 to } 72.9)\end{array}$ & $\begin{array}{c}28.2^{*} \\
\text { (7.8 to } 48.6)\end{array}$ & -31.2 \\
\hline $\begin{array}{l}\text { Oswestry } \\
\text { Disability index }\end{array}$ & $\begin{array}{c}10.1 \\
\text { (7.4 to } 12.9)\end{array}$ & $\begin{array}{c}6.0^{*} \\
(3.3 \text { to } 8.7 \text { ) }\end{array}$ & -4.1 & $\begin{array}{c}14.5 \\
(10.2 \text { to } 18.8)\end{array}$ & $\begin{array}{c}8.2^{*} \\
(5.8 \text { to } 10.6)\end{array}$ & -6.3 \\
\hline $\begin{array}{l}\mathrm{VO}_{2 \text { peak }} \\
\left(\mathrm{ml}^{1} \cdot \mathrm{kg}^{-1} \cdot \mathrm{min}^{-1}\right)\end{array}$ & $\begin{array}{c}34.3 \\
\text { (39.1 to } 57.1)\end{array}$ & $\begin{array}{c}37.4 \\
\text { (38.5 to } 50.3)\end{array}$ & 3.1 & $\begin{array}{c}37.9 \\
\text { (35.1 to } 53.2 \text { ) }\end{array}$ & $\begin{array}{c}40.1 \\
\text { (34.8 to } 53.2)\end{array}$ & 2.1 \\
\hline
\end{tabular}

Data are expresses as mean and confidence interval 95\%; $\mathrm{a}=0.05 .{ }^{*} \mathrm{p}<0.05$ for time effect (baseline vs. 12 weeks). Generalized estimated equation; Bonferroni correction.

Table 5. Quality of life for the moderate intensity aquatic training (MIT) and high intensity aquatic training (HIT) before and after 12 weeks of training.

\begin{tabular}{|c|c|c|c|c|c|c|}
\hline \multirow[t]{2}{*}{ Intention-to-treat analysis } & \multicolumn{3}{|c|}{ MIT } & \multicolumn{3}{|c|}{ HIT } \\
\hline & Baseline & 12 weeks & Change & Baseline & 12 weeks & Change \\
\hline PHYd & $\begin{array}{c}63.7 \\
\text { (55.1 to } 72.3 \text { ) }\end{array}$ & $\begin{array}{c}66.7^{*} \\
\text { (56.6 to } 77.3 \text { ) }\end{array}$ & 3.0 & $\begin{array}{c}52.9 \\
\text { (45.7 to } 60.2)\end{array}$ & $\begin{array}{c}65.0^{*} \\
\text { (58.6 to } 71.4)\end{array}$ & 12.1 \\
\hline PSYd & $\begin{array}{c}63.2 \\
(54.5 \text { to } 71.4)\end{array}$ & $\begin{array}{c}62.5 \\
\text { (56.0 to 68.9) }\end{array}$ & -0.7 & $\begin{array}{c}64.2 \\
\text { (54.2 to } 74.5)\end{array}$ & $\begin{array}{c}71.7 \\
\text { (60.9 to 82.3) }\end{array}$ & 7.5 \\
\hline $\mathrm{sOCd}$ & $\begin{array}{c}63.9 \\
\text { (46.8 to } 80.9)\end{array}$ & $\begin{array}{c}54.2^{\mathrm{a}} \\
(45.0 \text { to } 63.3)\end{array}$ & -9.7 & $\begin{array}{c}59.8 \\
\text { (47.6 to } 72.1)\end{array}$ & $\begin{array}{c}80.0^{\mathrm{b} *} \\
\text { (70.1 to } 89.9)\end{array}$ & 20.2 \\
\hline ENVd & $\begin{array}{c}60.4 \\
\text { (54.3 to } 66.5)\end{array}$ & $\begin{array}{c}64.8^{*} \\
\text { (56.9 to } 72.8)\end{array}$ & 4.4 & $\begin{array}{c}59.7 \\
\text { (53.8 to } 65.5)\end{array}$ & $\begin{array}{c}65.6^{*} \\
\text { (59.6- to } 71.6)\end{array}$ & 5.9 \\
\hline $\mathrm{OQL}$ & $\begin{array}{c}63.5 \\
\text { (50.9 to } 74.0)\end{array}$ & $\begin{array}{c}62.5 \\
\text { (47.5 to } 77.5)\end{array}$ & -1.0 & $\begin{array}{c}53.4 \\
\text { (43.4 to } 63.4 \text { ) }\end{array}$ & $\begin{array}{c}75.0^{*} \\
\text { (65.2 to } 84.8)\end{array}$ & 21.6 \\
\hline \multirow[t]{2}{*}{ Per protocol analysis } & \multicolumn{3}{|c|}{ MIT } & \multicolumn{3}{|c|}{ HIT } \\
\hline & Baseline & 12 weeks & Change & Baseline & 12 weeks & Change \\
\hline PHYd & $\begin{array}{c}60.1 \\
\text { (55.6 to } 64.6)\end{array}$ & $\begin{array}{c}56.2^{\mathrm{b}} \\
(52.4 \text { to } 60.1)\end{array}$ & 3.9 & $\begin{array}{c}55.9 \\
(46.2 \text { to } 65.7)\end{array}$ & $\begin{array}{c}63.4^{\mathrm{a}} \\
(59.6 \text { to } 67.2)\end{array}$ & 7.5 \\
\hline PSYd & $\begin{array}{c}60.4 \\
\text { (55.8 to } 65.0)\end{array}$ & $\begin{array}{c}54.2^{\mathrm{a}} \\
(51.3 \text { to } 57.0)\end{array}$ & -6.2 & $\begin{array}{c}57.4 \\
(48.8 \text { to } 65.9)\end{array}$ & $\begin{array}{c}67.7^{\mathrm{b}} \\
(61.7 \text { to } 73.7)\end{array}$ & 10.3 \\
\hline SOCd & $\begin{array}{c}63.9 \\
(46.8 \text { to } 80.9)\end{array}$ & $\begin{array}{c}54.2^{\mathrm{a}} \\
(45.0 \text { to } 63.3)\end{array}$ & -9.7 & $\begin{array}{c}59.2 \\
(44.4 \text { to } 74.1)\end{array}$ & $\begin{array}{c}83.3^{\mathrm{b} *} \\
\text { (73.3 to 93.3) }\end{array}$ & 24.1 \\
\hline ENVd & $\begin{array}{c}60.4 \\
(54.3 \text { to } 66.5)\end{array}$ & $\begin{array}{c}64.8^{*} \\
\text { (56.9 to } 72.8)\end{array}$ & 4.4 & $\begin{array}{c}60.4 \\
(53.3 \text { to } 67.5)\end{array}$ & $\begin{array}{c}67.2^{*} \\
(60.5 \text { to } 73.9)\end{array}$ & 6.8 \\
\hline $\mathrm{OQL}$ & $\begin{array}{c}62.5 \\
\text { (50.9 to } 67.9)\end{array}$ & $\begin{array}{c}62.5 \\
\text { (47.5 to } 77.5)\end{array}$ & -1.0 & $\begin{array}{c}56.9 \\
(45.9 \text { to } 67.9)\end{array}$ & $\begin{array}{c}78.1^{*} \\
\text { (67.9 to } 88.3)\end{array}$ & 21.2 \\
\hline
\end{tabular}

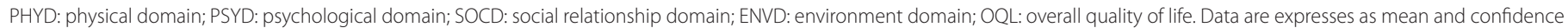
interval 95\%; $a=0.05 .{ }^{*} p<0.05$ for time effect (baseline vs. 12 weeks). Different letters: $p<0.05$ for groups effect (MIT vs. HIT). Generalized estimated equation; Bonferroni correction. 
In the analysis of the ES, the comparison of the MIT and HIT groups showed a large magnitude of effect for the following domains and their respective analyses: the physical domain in the intention-to-treat (0.99 [0.12 to 1.86$])$ and in the protocol analyses (0.99 [0.12 to 1.86$])$, the psychological domain in the protocol analysis (1.40 [0.48 to 2.32]), and the social domain in the intention-to-treat (1.30 [0.43 to 2.16]) and in the protocol analyses (1.59 [0.65 to 2.53]). A moderate magnitude of effect was shown for the disability index in the intention-to-treat analysis (0.56 [-0.13 to 1.26$]$ ), and for general quality of life domain in the intention-to-treat ( 0.53 [-0.27 to 1.34$])$ and protocol analyses $(0.68$ [-0.17 to 1.53$])$. Small effect was observed for pain in the intentionto-treat (0.30 [-0.39 to 1.00] and in the protocol analyses $(0.27[-0.45$ to 0.99$])$, for the disability index in the protocol analysis (0.40 [-0.31 to 1.11]), for $\mathrm{VO}_{2 \text { peak }}$ in the intention-to-treat (0.07 [0.63 to 0.76]) and in the protocol analyses (0.03 [-0.72 to 0.77]), for the psychological domain in the intention-to-treat analysis (0.46 [-0.34 to 1.26]), for the environmental domain in the intention-to-treat (0.06 [-0.73 to 0.85]) and the protocol analyses ( 0.17 [-0.65 to 2.53]), and for general quality of life domain in the intention-to-treat analysis (0.53 [-0.27 to 1.34]).

\section{Discussion}

Overall, the results demonstrated that both the HIT and MIT interventions were effective in improving pain and disability in people with chronic low back pain. Regarding quality of life, the group that performed the intervention at a higher intensity experienced more significant results, highlighting the importance of the social domain and general quality of life. Both groups presented significant improvements in the physical and environmental domains. The results agree in part with our hypothesis, since we believed that both groups would show improvements in the outcomes evaluated. However, we believed that the high-intensity group would stand out in the improvements found, due to our hypothesis that they would experience a more marked improvement in physical capacity. Contrary to our belief, this did not change in both groups after the intervention.

In relation to pain and disability results, these corroborate the literature that shows that aerobic exercises in the aquatic environment are effective for improvements in these parameters ${ }^{1,15,16}$. It is believed that physical exercise causes stress-induced analgesia, releasing cortisol and adrenaline into the bloodstream, and consequently increasing the practitioner's pain threshold'. Chatzitheodourou et al..$^{17}$ suggest that this behavior is maximized at higher intensities, however, our study does not support this theory. It appeared that regardless of training intensity, both groups experienced similar improvements in both pain and disability. In this sense, Hoffman \& Al'Absi22 believe that intensities above $50 \%$ of maximal oxygen uptake $\left(\mathrm{VO}_{2 \max }\right)$ are already sufficient to provide an analgesic effect of exercise in patients with chronic low back pain. In the present study, the MIT group started training at an intensity of $85 \%$ of HRVT2 and progressed up to $95 \%$ of HRVT2, and thus these intensities were enough to observe a significant improvement in pain and disability.

In addition, it should be noted that these results demonstrate that aerobic exercise performed as deep-water running, whether at mode- rate or high intensity, does not present adverse effects on patients, such as increased pain or disability, but rather a significant reduction in these parameters. In this way, high intensities can be prescribed for individuals with chronic low back pain in deep-water walking/running with safety. Still, we emphasize that aquatic exercise modalities present important characteristics, especially for patients with musculoskeletal problems involving pain. Among these, we highlight the possibility of practicing aerobic exercises at higher intensities due to reduced joint impact ${ }^{23,24}$ and spinal decompression ${ }^{11}$. Along with reaping these benefits, the aquatic environment provides characteristics of greater security, greater tolerance of the exercise, and, consequently, a more pleasant experience with greater adhesion to an aquatic exercise regimen. Finally, it should be noted that in the literature, reductions in pain scores of greater than $20 \%$ are considered clinically relevant and in the present study, there was a mean reduction in pain scores of $60 \%$ in both intervention group ${ }^{25}$.

According to data published in the literature, the improvement of pain and disability seems to be related to improvements in physical fitness ${ }^{5-7}$ and in this context, the present study evaluated $\mathrm{VO}_{2 \text { peak }}$ as a means of measuring physical fitness. However, the two interventions tested were not effective in improving this parameter; they were only effective in maintaining it, which demonstrates that improvements in pain and disability can occur even if there are no improvements in physical fitness. In the literature, studies that used frequencies of three or more sessions per week for aerobic training showed significant improvements in $\mathrm{VO}_{2 \text { peak }} \mathrm{OrVO}_{2 \text { max }}$ in patients with chronic low back pain ${ }^{14,26}$. In elderly patients, Kanitz et al. ${ }^{27}$ observed a significant increase in $\mathrm{VO}_{\text {2peak }}$ after a 12-week deep-water running intervention with three sessions per week. Thus, the weekly frequency of the present study - twice per week - was perhaps not enough to provide significant improvements in cardiorespiratory parameters. In addition, the participants of the present study started the study with mean $\mathrm{VO}_{2 \text { peak }}$ values of $44.75 \mathrm{ml} . \mathrm{kg}^{-1} . \mathrm{min}^{-1}$, values that classify cardiorespiratory fitness as "good"for men and "excellent"for women ${ }^{28}$. Thus, the high initial $\mathrm{VO}_{2 \text { peak }}$ values of the participants in the present study reflect a smaller amplitude for the possibility of improvements, compared to sedentary or elderly participants, which characterized the participants of the aforementioned studies. Thus, once again, it is believed that a higher weekly frequency may have been more effective in providing improvements in cardiorespiratory parameters. In addition, it is believed that because the training and the assessment of physical fitness were carried out in different environments, perhaps there was no transfer of the benefits of training to the assessment. However, it is noteworthy that the assessment in land environment was chosen precisely to verify the benefits of the aquatic modality in the environment in which the participants live, and the maximum test in aquatic environment was performed only for the training prescription.

In contrast to the aforementioned outcomes, differences in the quality of life parameter were evident between the groups, demonstrating that exercise intensity may have an influence on this parameter in individuals with chronic low back pain. The environmental and physical domains were the only areas that improved equally with the interventions. In relation to the physical domain, which is related to pain, discomfort, energy, and sleep ${ }^{29}$, it showed significant improvements in both groups and no difference between them. This result corroborates the findings of the present study related to pain and disability. 
However, the improvement in physical domain was only observed in the intention-to-treat analysis. Regarding physical quality of life, since the MIT group showed different behavior pertaining to this outcome in both analyses, and the HIT demonstrated similar behavior in both analyses, one should be cautious in attributing beneficial effects to aquatic training of moderate intensity.

Another important domain of quality of life is the psychological domain, which is related to positive feelings and the capacity for thinking, learning, and self-esteem ${ }^{29}$. Significantly higher scores for this domain were presented in the HIT group during the post-training period, but only in the analysis per protocol, which brings us to recognize a direct relationship between this outcome and the protocol of high intensity performed. The high-intensity exercise may have presented a greater challenge to the practitioners, which may lead to more positive behavior over time ${ }^{30,31}$. In addition, in both analyses, the social domain and general quality of life showed significant improvements, but only in the HIT group. Thus, the high-intensity intervention seems to be more effective for improvements in quality of life compared to the moderateintensity intervention.

The literature indicates that improvements in pain and disability directly reflect improvements in the quality of life of patients with chronic low back pain ${ }^{32}$. In the present study, the groups significantly improved in both the pain and disability parameters, but these improvements were reflected more in the group that trained at high intensity. The influence of intervention intensity on quality of life is not elucidated in the literature, as no studies have been found that observe the effects of different training intensities on the quality of life in patients with chronic low back pain or in any other patient population. Thus, the results of this study appear to be innovative in the literature, and they introduce a gap for further research.

The main limitations of this study were the small number of participating patients and the low weekly frequency of training for participants already considered as active with good-to-excellent physical fitness ratings. Thus, for future studies, a larger sample size and training at a higher weekly frequency are suggested.

From the results of the present study, we can conclude that aerobic training in aquatic environments seems to be effective for improving pain symptoms and reducing the disability of people with chronic low back pain. These improvements seem to be independent of the intensity at which the training is performed, including high-intensity training that proved safe for these participants. Still, these improvements are not necessarily related to an increase in physical capacity, since $\mathrm{VO}_{2 \text { peak }}$ values were maintained throughout the intervention in both groups. In addition, improvement in pain and disability does not directly reflect the status of all areas of quality of life. In this case, the group that performed the intervention at high intensity highlighted unique domains, as they experienced more significant improvements in the social, psychological, and general quality of life domains. In contrast, the physical and environmental domains improved similarly in both groups.

Thus, aerobic exercise of deep-water walking/running may be indicated for patients affected by chronic low back pain. Furthermore, for the participants in this study who were classified as having good-toexcellent physical fitness, the two intensities, moderate and high, can also be indicated without any impairment in the parameters of pain or disability. However, in order to have a positive impact on the quality of life of these patients, high-intensity training is more effective. As for improvement in cardiorespiratory fitness, we suggest a higher weekly frequency of training. Nonetheless, it is emphasized that the interventions were effective in maintaining cardiorespiratory fitness.

\section{Acknowledged}

The authors thanks specially to CAPES and CNPq Brazilian Government Association for its support to this Project. We gratefully acknowledge all the participants who participated in this research and made this project possible. We are grateful for the collaboration of GPAT researchers, especially colleagues: Karen Przybisz Rosa and Felipe Schuch, who helped develop the study design and some data collections.

\section{Conflict of interest}

The authors do not declare a conflict of interest.

\section{Bibliography}

1. Cuesta-Vargas Al, Romero JCG, Manzanares MTL, González-Sánchez M. Efectividad clínica de un programa de fisioterapia multimodal complementado con carrera acuática de alta intensidad sobre la lumbalgia. Un estudio con evaluación previa en el postest. Fisioterapia. 2010;32:17-24.

2. Nascimento PRC do, Costa LOP. Prevalência da dor lombar no Brasil: uma revisão sistemática. Cad Saude Publica. 2015;31:1141-56.

3. Fuentes PC, Hervías MTF, Barba MM-C, Matamoros DJC. Efectos de la hidroterapia en el dolor lumbar crónico: fisioterapia basada en la evidencia. Rev Iberoam Fisiotery Kinesiol. 2007;10:97-102.

4. Hinman RS, Heywood SE, Day AR. Aquatic physical therapy for hip and knee osteoarthritis: results of a single-blind randomized controlled trial. Phys Ther. 2007;87:32-43.

5. Olson DA, Kolber MJ, Patel C, Pabian P, Hanney WJ. Aquatic exercise for treatment of low-back pain: a systematic review of randomized controlled trials. Am J Lifestyle Med. 2013;7:154-60.

6. Rinkus KM, Knaub MA. Clinical and diagnostic evaluation of low back pain. In: Seminars in Spine Surgery. Elsevier; 2008. p. 93-101.

7. Waller B, Lambeck J, Daly D. Therapeutic aquatic exercise in the treatment of low back pain: a systematic review. Clin Rehabil. 2009;23:3-14.

8. Dundar U, Solak O, Yigit I, Evcik D, Kavuncu V. Clinical effectiveness of aquatic exercise to treat chronic low back pain: a randomized controlled trial. Spine. 2009;34:1436-40.

9. Craig Jr AB, Dvorak M. Thermal regulation during water immersion. J Appl Physiol. 1966;21:1577-85.

10. Bender T, Karagülle Z, Bálint GP, Gutenbrunner C, Bálint PV, Sukenik S. Hydrotherapy, balneotherapy, and spa treatment in pain management. Rheumatol Int. 2005;25:220-4.

11. Dowzer C, Reilly T. Deep-water running. Sport Exerc Inj. 1998;4:56-61.

12. Kanitz AC, Reichert T, Liedtke GV, Pinto SS, Alberton CL, Antunes AH, et al. Maximal and anaerobic threshold cardiorespiratory responses during deep-water running. RevBras Cineantropometria Desempenho Hum. 2015;17:41-50.

13. Bello Al, Kalu NH, Adegoke BOA, Agyepong-Badu S. Hydrotherapy versus land-based exercises in the management of chronic low back pain: A comparative study. J Musculoskelet Res. 2010;13:159-65.

14. Baena-Beato PA, Arroyo-Morales M, Delgado-Fernêndez M, Gatto-Cardia MC, Artero EG. Effects of different frequencies (2-3 days/week) of aquatic therapy program in adults with chronic low back pain. A non-randomized comparison trial. Pain Med. 2013;14:145-58.

15. Cuesta-Vargas Al, García-Romero JC, Arroyo-Morales M, Diego-Acosta ÁM, Daly DJ. Exercise, manual therapy, and education with or without high-intensity deep-water running for nonspecific chronic low back pain: a pragmatic randomized controlled trial. Am J Phys Med Rehabil. 2011;90:526-38.

16. Cuesta-Vargas Al, Adams N, Salazar JA, Belles A, Hazañas S, Arroyo-Morales M. Deep water running and general practice in primary care for non-specific low back pain versus general practice alone: randomized controlled trial. Clin Rheumatol. 2012;31:1073-8. 
Deep-water running training at moderate intensity and high intensity improves pain, disability, and quality of life in patients with chronic low back pain: a randomized clinical trial

17. Chatzitheodorou D, Kabitsis C, Malliou P, Mougios V. A pilot study of the effects of highintensity aerobic exercise versus passive interventions on pain, disability, psychological strain, and serum cortisol concentrations in people with chronic low back pain. Phys Ther. 2007:87:304-12.

18. Schulz KF, Altman DG, Moher D. CONSORT 2010 statement: updated guidelines for reporting parallel group randomised trials. BMC Med. 2010;8:18.

19. Medicine AC of S. Diretrizes de ACSM para os testes de esforço e sua prescrição. Guanabara Koogan; 2003.

20. Howley ET, Bassett DR, Welch HG. Criteria for maximal oxygen uptake: review and commentary. Med Sci Sports Exerc. 1995;27:1292.

21. Cohen J. Statistical power analysis for the behavioral sciences. Routledge; 2013

22. Hoffman R, al'Absi M. The effect of acute stress on subsequent neuropsychological test performance (2003). Arch Clin Neuropsychol. 2004;19:497-506.

23. Alberton CL, Tartaruga MP, Pinto SS, Cadore EL, Antunes AH, Finatto P, et al. Vertical ground reaction force during water exercises performed at different intensities. Int J Sports Med. 2013;34:881-7.

24. Alberton CL, Antunes AH, Beilke DD, Pinto SS, Kanitz AC, Tartaruga MP, et al. Maximal and ventilatory thresholds of oxygen uptake and rating of perceived exertion responses to water aerobic exercises. J Strength Cond Res. 2013;27:1897-903.

25. Keller A, Hayden J, Bombardier C, Van Tulder M. Effect sizes of non-surgical treatments of non-specific low-back pain. Eur spine J. 2007;16:1776-88.
26. Chan CW, Mok NW, Yeung EW. Aerobic exercise training in addition to conventional physiotherapy for chronic low back pain: a randomized controlled trial. Arch Phys Med Rehabil. 2011;92:1681-5.

27. Kanitz AC, Delevatti RS, Reichert T, Liedtke GV, Ferrari R, Almada BP, et al. Effects of two deep water training programs on cardiorespiratory and muscular strength responses in older adults. Exp Gerontol. 2015;64:55-61.

28. Herdy AH, Caixeta A. Brazilian cardiorespiratory fitness classification based on maximum oxygen consumption. Ara Bras Cardiol. 2016;106:389-95.

29. Fleck M, Louzada S, Xavier M, Chachamovich E, Vieira G, Santos L, et al. Aplicação da versão em português do instrumento abreviado de avaliação da qualidade de vida" WHOQOL-bref". Rev Saude Publica. 2000;34:178-83.

30. Heisz JJ,Tejada MGM, Paolucci EM, Muir C. Enjoyment for High-Intensity Interval Exercise Increases during the First Six Weeks of Training: Implications for Promoting Exercise Adherence in Sedentary Adults. PLoS One. 14 de dezembro de 2016:11:e0168534. Available at: https://doi.org/10.1371/journal.pone.0168534

31. Bartlett JD, Close GL, MacLaren DPM, Gregson W, Drust B, Morton JP. High-intensity interval running is perceived to be more enjoyable than moderate-intensity continuous exercise: implications for exercise adherence. J Sports Sci. 2011;29:547-53.

32. Stefane T, Santos AM, Marinovic A, Hortense P. Dor lombar crônica: intensidade de dor, incapacidade e qualidade de vida. Acta Paul Enferm. 2013;26. 